\title{
Limbic and Motor Circuitry Underlying Footshock-Induced Reinstatement of Cocaine-Seeking Behavior
}

\author{
Krista McFarland, Susan B. Davidge, Christopher C. Lapish, and Peter W. Kalivas \\ Department of Physiology and Neuroscience, Medical University of South Carolina, Charleston, South Carolina 29425
}

The role of limbic, cortical, and striatal circuitry in a footshock reinstatement model of relapse to cocaine seeking was evaluated. Transient inhibition of the central extended amygdala [CEA; including the central nucleus of the amygdala (CN), ventral bed nucleus of the stria terminalis (BNSTv), and nucleus accumbens shell (NAshell)], ventral tegmental area (VTA), and motor circuitry [including the dorsal prefrontal cortex (PFCd), nucleus accumbens core (NAcore), and ventral pallidum (VP)] blocked the ability of footshock stress to reinstate lever pressing previously associated with cocaine delivery. However, inhibition of the basolateral amygdala, mediodorsal nucleus of the thalamus, or the ventral prefrontal cortex had no effect on drug-seeking behavior. These data suggest that footshock stress activates limbic circuitry of the CEA that, via the VTA, activates motor output circuitry responsible for producing lever press responding. Consistent with this notion, the $\mathrm{D}_{1} / \mathrm{D}_{2}$ dopamine receptor antagonist fluphenazine blocked footshock-induced reinstatement when infused into the PFCd. Further, inhibition of the NAshell blocked a footshock-induced increase in dopamine within the PFC and concomitantly blocked reinstatement responding. Also supporting the idea of a CEA-VTA-motor circuit in stress-induced reinstatement of cocaine seeking, inactivation of the PFCd was shown to block stress-induced glutamate release within the NAcore while concurrently inhibiting reinstatement responding. Taken together, these data suggest that footshock activates limbic circuitry in the CEA, which in turn activates a VTA dopamine projection to the PFCd. The rise in dopamine within the PFCd initiates reinstatement via a glutamatergic projection to the NAcore.

Key words: accumbens; cocaine; self-administration; reinstatement; footshock; prefrontal cortex

\section{Introduction}

The biggest challenge to successful treatment of cocaine addiction is preventing craving and relapse, which are hallmarks of the disease. In human addicts and animal reinstatement models of relapse three different kinds of stimuli are capable of eliciting renewed drug seeking: stress (Erb et al., 1996; Ahmed and Koob, 1997), cues predicting drug availability (Grimm and See, 2000; Weiss et al., 2001), and reexposure to the previously selfadministered drug (Neisewander et al., 1996; McFarland and Kalivas, 2001). Understanding the neural circuitry by which these various stimuli elicit responding is a prerequisite to developing adequate pharmacotherapies for addiction.

In human addicts, imaging studies have shown that craving for cocaine is associated with metabolic activation of the prefrontal cortex, amygdala, and striatal complex (Childress et al., 1999; Volkow et al., 1999; Garavan et al., 2000; Kilts et al., 2001). Notably, these nuclei fall within a well characterized circuit in the basal forebrain, termed the "motive circuit" (Mogenson et al., 1980; Kalivas et al., 1993a). Behavioral responding to biologically relevant stimuli is associated with altered electrophysiological ac-

Received Sept. 11, 2003; revised Dec. 2, 2003; accepted Dec. 3, 2003.

This research was supported in part by United States Public Health Service Grants DA12513, MH40817, and DA03906 and a postdoctoral National Research Service Award DA05978 (K.M.).

Correspondence should be addressed to Krista McFarland, Department of Physiology and Neuroscience, Medical University of South Carolina, 173 Ashley Avenue, Room 403 BSB, Charleston, SC 29425. E-mail: mcfarlk@musc.edu. D01:10.1523/JNEUROSCI.4177-03.2004

Copyright $\odot 2004$ Society for Neuroscience $\quad$ 0270-6474/04/241551-10\$15.00/0 tivity and extracellular neurotransmitter levels within many nuclei of the motive circuit (Schultz et al., 1993; Kosobud et al., 1994; Westerink, 1995; Cousins et al., 1999; Bradberry et al., 2000; Carelli and Ijames, 2000; Chang et al., 2000). Furthermore, lesions of the nucleus accumbens (NA), prefrontal cortex (PFC), amygdala, ventral pallidum (VP), or mediodorsal nucleus (MD) have been shown to disrupt responding maintained by food or drugs of abuse as well as responding maintained by stimuli predictive of such reinforcement (Brown and Fibiger, 1993; McAlonan et al., 1993; Baker et al., 1994, 1996; Gong et al., 1997; Parkinson et al., 1999; Alderson et al., 2001). Thus this circuitry serves as a logical target in the search for the neural basis of reinstatement or relapse.

Topographic analysis of the interconnections among the nuclei comprising the motive circuit has established two subcircuits: one subcircuit composed of the ventral PFC (PFCv), shell of the accumbens (NAshell), medial VP, amygdala, and the ventral tegmental area (VTA), which is connected more intimately with limbic structures, and another subcircuit composed of the dorsal PFC (PFCd), core of the accumbens (NAcore), dorsolateral VP, and substantia nigra, which is interconnected more extensively with motor structures (Zahm and Brog, 1992; Kalivas et al., 1993a; Groenewegen et al., 1996). Traditionally, they have been termed the "limbic" and "motor" subcircuits in deference to this anatomical specificity.

Previous research has suggested that cocaine-primed reinstatement of cocaine seeking depends mainly on the motor sub- 
circuit within the motive circuit [i.e., the PFCd, NAcore, and VP (McFarland and Kalivas, 2001)]. However, in humans it is likely that relatively few instances of relapse are attributable to noncontingent drug exposure. For this reason the present study examines the role of the motive circuit in an animal model of stressinduced relapse in an attempt to assess the degree of convergence (or divergence) between circuitry underlying cocaine-induced versus footshock-induced drug seeking. First the nuclei within the motive circuit were inactivated individually to assess their involvement in footshock-induced reinstatement; then the functional connectivity of these nuclei was assessed.

\section{Materials and Methods}

Animal housing. The subjects were 220 male Sprague Dawley rats, purchased from Charles River Laboratories (Indianapolis, IN) weighing 225-250 gm at arrival. Subjects were housed in an Association for the Assessment and Accreditation of Laboratory Animal Care (AAALAC) accredited facility on a $12 \mathrm{hr}$ light/dark cycle (lights on, 7 P.M.). Before surgery the animals had unlimited access to food and water and were housed in pairs. After surgery each was housed individually and, after 1 week for recovery, food was limited to $20 \mathrm{gm} / \mathrm{d}$. Water continued to be available ad libitum. All procedures were approved by the Institutional Animal Care and Use Committee at the Medical University of South Carolina and were in accordance with National Institutes of Health Guide for the Care and Use of Laboratory Animals.

Surgery. Surgery followed 1 week of acclimation to handling. Subjects in the cocaine self-administration experiments were implanted with indwelling jugular catheters and guide cannulas to be used for microinjections or microdialysis. Surgeries were conducted under ketamine (87.5 $\mathrm{mg} / \mathrm{kg}$ Ketaset, Fort Dodge Animal Health, Fort Dodge, IA) and xylazine ( $5 \mathrm{mg} / \mathrm{kg}$ Rompum, Bayer, Shawnee Mission, KS) anesthesia. A threaded guide cannula (C313G, Plastics One, Roanoke, VA) was attached to Silastic tubing inserted into the right jugular vein $(2.7-3.0 \mathrm{~cm})$ and then was run subcutaneously and externalized via a $3 \mathrm{~mm}$ biopsy hole between the shoulder blades. After surgery the catheter was flushed daily with 0.2 $\mathrm{ml}$ of heparin $(100 \mathrm{IU} / \mathrm{ml})$ and cefazolin antibiotic $(100 \mathrm{mg} / \mathrm{ml})$ in sterile saline vehicle to help protect against infection and catheter occlusion.

All guide cannulas were implanted according to the atlas of Paxinos and Watson (1998). Microinjection cannulas were aimed at one of 10 nuclei by using the following coordinates (given in $\mathrm{mm}$ with respect to bregma): PFC dorsal or ventral, anteroposterior $(\mathrm{A} / \mathrm{P})+3.0$, mediolat$\operatorname{eral}(\mathrm{M} / \mathrm{L})+0.7$, dorsoventral $(\mathrm{D} / \mathrm{V})-2.2 ; \mathrm{NAshell}, \mathrm{A} / \mathrm{P}+1.5, \mathrm{M} / \mathrm{L}+0.6$, $\mathrm{D} / \mathrm{V}-6.5$; NAcore, $\mathrm{A} / \mathrm{P}+1.2, \mathrm{M} / \mathrm{L}+1.6, \mathrm{D} / \mathrm{V}-6.5 ; \mathrm{VP}, \mathrm{A} / \mathrm{P}-0.25$, $\mathrm{M} / \mathrm{L}+2.4, \mathrm{D} / \mathrm{V}-7.0$; ventral bed nucleus of the stria terminalis (BNSTv), $\mathrm{A} / \mathrm{P}-0.4, \mathrm{M} / \mathrm{L}+3.5, \mathrm{D} / \mathrm{V}-6.2$ at $15^{\circ}$ from vertical; central nucleus of the amygdala $(\mathrm{CN}), \mathrm{A} / \mathrm{P}-2.1, \mathrm{M} / \mathrm{L}+4.0, \mathrm{D} / \mathrm{V}-7.2$; basolateral amygdala (BLA), A/P -2.5, M/L +4.7, D/V -7.6; MD, A/P -2.5, M/L +0.6, $\mathrm{D} / \mathrm{V}-4.5$; VTA, A/P $-5.2, \mathrm{M} / \mathrm{L}+0.85, \mathrm{D} / \mathrm{V}-8.0$ at $6^{\circ}$ from vertical. Coordinates for microdialysis cannulas were NAcore $\mathrm{A} / \mathrm{P}+1.2$, $\mathrm{M} / \mathrm{L}+2.5, \mathrm{D} / \mathrm{V}-4.7$ at $6^{\circ}$ from vertical and PFC A/P +3.0, M/L + 2.2, $\mathrm{D} / \mathrm{V}-2.0$ at $20^{\circ}$ from vertical. Guide cannulas were secured to the skull with dental cement and jeweler's screws.

Self-administration training. Animals were allowed 1 week of recovery before beginning behavioral training. All training was conducted in standard operant chambers equipped with two retractable levers. Rats were trained initially in the lever press response. Food was removed for $12 \mathrm{hr}$, and then a single $15 \mathrm{hr}$ training session was conducted. During this session each press on the correct lever was reinforced by delivery of a single $45 \mathrm{mg}$ food pellet. On the next day the subjects began acquisition of cocaine self-administration. Correct lever presses resulted in cocaine infusion $(0.25 \mathrm{mg} / \mathrm{kg}$ in $0.05 \mathrm{ml}$ over $3 \mathrm{sec})$ and illumination of a stimulus light over the lever. The light remained on for $20 \mathrm{sec}$, during which time correct lever presses were counted but resulted in no further cocaine infusion. After the $20 \mathrm{sec}$ timeout the light was extinguished, and the first press on the active lever again resulted in cocaine delivery. Presses on the inactive lever never resulted in cocaine delivery. Sessions lasted for $2 \mathrm{hr}$ or until 200 reinforcements were earned. Animals remained in selfadministration training until they met a maintenance criterion requiring that the average responding over three consecutive sessions varied by $<10 \%$.

Extinction and reinstatement testing. Once a rat met the maintenance criterion, it remained in its home cage for $5 \mathrm{~d}$ before being returned to the operant chamber, where it was housed for the duration of extinction and reinstatement testing. The $5 \mathrm{~d}$ period in the home cage was chosen on the basis of research suggesting that there are time-dependent changes in footshock-induced reinstatement, with optimal responding between 6 and $12 \mathrm{~d}$ after the last self-administration session (Shalev et al., 2001). An extinction model of reinstatement was chosen to isolate the effects of shock presentation on responding. Thus, after extinction, responding was at low levels, and the effects of stress on behavioral responding and neurochemistry could be isolated best.

During extinction sessions responding on the active lever resulted in illumination of the stimulus light for $20 \mathrm{sec}$ and an infusion of saline rather than cocaine. Each session lasted $1 \mathrm{hr}$; however, multiple extinction sessions were conducted each day. Subjects experienced a $1 \mathrm{hr}$ extinction session, followed by a $1 \mathrm{hr}$ break (in which the house light was extinguished and the levers retracted), and then another extinction session. This pattern continued until responding on the active lever fell to $<10 \%$ of the average responding during maintenance. Once responding met this criterion on a given day, the sessions were discontinued for the day. Extinction training continued in this manner until subjects met the extinction criterion during the first daily session.

On reinstatement test day a footshock session preceded behavioral testing. Intermittent shock $(0.75 \mathrm{~mA}, 0.5 \mathrm{sec}$ duration $)$ was delivered on a variable interval-40 sec (VI-40“) schedule (10-70 sec range) for $10 \mathrm{~min}$. Immediately after the shock session the house light was illuminated, and the levers were inserted into the chamber. Lever presses were counted but resulted in no programmed consequences.

Microinjections. Subjects were microinjected in the self-administration chamber before reinstatement testing. Obdurators were removed and bilateral infusion cannulas (33 gauge) were inserted, extending $1 \mathrm{~mm}$ beyond the tip of the guide cannulas (except for infusions into the PFCv, where the microinjection cannulas extended $3 \mathrm{~mm}$ beyond the guide cannula). All infusions were made in a volume of $0.3 \mu \mathrm{l}$ over $1 \mathrm{~min}$, and an additional $1 \mathrm{~min}$ was allowed for diffusion before the microinfusion cannulas were removed. Obdurators were replaced, and the operant chamber was closed. Baclofen and muscimol (bac/mus) were infused at doses of 0.3 and $0.03 \mathrm{nmol} /$ side, respectively, and fluphenazine was infused at a dose of $10 \mathrm{nmol} / \mathrm{side}$.

Microdialysis. Microdialysis probes were constructed with inlet and outlet tubing (made of fused silica) inserted into a semipermeable membrane with $2 \mathrm{~mm}$ active length. They were inserted (with the active membrane beginning $2 \mathrm{~mm}$ beyond the guide cannula) and cemented into place the evening of the second extinction day. Dialysis was conducted on the first day after rats met the extinction criterion in the first session (day 4 or 5 for all subjects that were tested). Thus dialysis buffer [containing (in mM): 5 glucose, $2.5 \mathrm{KCl}, 140 \mathrm{NaCl}, 1.4 \mathrm{CaCl}_{2}, 1.2 \mathrm{MgCl}_{2}, 0.15 \% \mathrm{PBS}$, $\mathrm{pH} 7.4$ ] was perfused through the probe $(2 \mu \mathrm{l} / \mathrm{hr})$ beginning $36-60 \mathrm{hr}$ after probe implantation. After $3 \mathrm{hr}$ of perfusion baseline samples were collected at $10 \mathrm{~min}$ intervals for $2 \mathrm{hr}$. All samples were collected into $20 \mu \mathrm{l}$ of mobile phase [containing (in mM): 150 sodium dihydrogen phosphate monobasic, 4.76 citric acid, 3 sodium dodecyl sulfate plus $50 \mu \mathrm{M}$ EDTA, $10 \%$ methanol v/v, $15 \%$ acetonitrile $\mathrm{v} / \mathrm{v}, \mathrm{pH} 5.6$ ] to help stabilize monoamines. After baseline collection the subjects received microinfusions and the shock prime and subsequently were tested for reinstatement. Samples were collected at $10 \mathrm{~min}$ intervals for the duration of the experiment and then stored at $-80^{\circ} \mathrm{C}$ until assayed for glutamate (GLU) or dopamine (DA) content.

Quantification of DA and GLU. Before analysis the samples were thawed and divided so they could be analyzed for both DA and GLU content. For DA analysis the samples were placed in an ESA (Chelmsford, MA) model 540 autosampler connected to an HPLC system with electrochemical detection. Separation was achieved by pumping the samples through a $15 \mathrm{~cm} \mathrm{C}_{18}$ reverse phase column (ESA) and then were reduced/ oxidized by coulometric detection. Three electrodes were used: a guard cell $(+400 \mathrm{mV})$, a reduction analytical electrode $(-175 \mathrm{mV})$, and an 
oxidation analytical electrode $(+250 \mathrm{mV})$. Area under the peak was determined with ESA software.

Concentration of GLU in the samples was determined by using HPLC with fluorometric detection. Samples were loaded by an autosampler (Gilson Medical Supplies, Middleton, WI) that performed a precolumn derivitization with $o$-pthalaldehyde. Amino acids then were separated with a reverse phase $\mathrm{C}_{18}(15 \mathrm{~cm})$ column. GLU was detected via a fluorescence spectrophotometer (Linear Fluor LC 305, ESA) with an excitation wavelength of $336 \mathrm{~nm}$ and an emission wavelength of $440 \mathrm{~nm}$. Peaks heights were recorded and measured.

Food reinstatement. Previous studies have demonstrated that at least some of the circuitry involved in renewed cocaine-seeking behavior is specific to drug-related responding because inactivation of the VTA, PFCd, or NAcore did not block the ability of food to elicit renewed food-seeking behavior after extinction. However, in previous studies, nuclei within the central extended amygdala were not examined. Therefore, the NAshell and CN (as representative of nuclei within the CEA) were examined for their involvement in the ability of a food prime to elicit food-seeking behavior. Rats in the food reinstatement studies (FR) were fed $20 \mathrm{gm}$ of food daily beginning 1 week after surgery. Rats were trained to lever press on an FR-1 schedule for reinforcement consisting of a single $45 \mathrm{mg}$ food pellet in daily $2 \mathrm{hr}$ sessions. The timeout used for food studies was $5 \mathrm{sec}$ (rather than $20 \mathrm{sec}$ for cocaine studies). After acquisition of the lever press, the response requirement was increased to an FR-2 and then an FR-5. On each schedule, responding had to meet a stability requirement ( $<10 \%$ variation in responding across $3 \mathrm{~d}$ consecutively) before the next schedule was instituted. Once the subjects were responding stably on an FR-5 schedule, the rats were moved to the extinction phase in which lever presses no longer resulted in food delivery. The extinction criterion required that lever press responding average $<10 \%$ of responding during maintenance on the FR-5 schedule. On the day after this criterion was met, the subjects experienced a reinstatement test session in which two food pellets were placed in the food cup to begin the session, and a single food pellet was delivered every $2 \mathrm{~min}$ for the first 20 min of the reinstatement session. Lever presses still did not result in food delivery. Two food reinstatement trials were conducted and were separated by additional extinction trials to ensure rats again met the extinction criterion between test sessions. Before reinstatement sessions the subjects received a microinfusion of either saline or baclofen and musci$\mathrm{mol}(0.3$ and $0.03 \mathrm{nmol} /$ side in $0.3 \mu \mathrm{l}$, respectively) in random order.

Locomotor activity. Motor activity was monitored in clear Plexiglas boxes $(22 \times 43 \times 33 \mathrm{~cm})$. Each box was monitored by a series of 16 photo beams ( 8 on each horizontal axis) measuring horizontal activity and eight photo beams measuring vertical activity. Beam breaks were detected, counted, and recorded by a personal computer running Digiscan software. Each test period consisted of a $1 \mathrm{hr}$ acclimation period before testing. After habituation, each subject was removed from its cage, given a microinfusion of either saline or bac/mus $(0.3 / 0.03 \mathrm{nmol} / \mathrm{side}$ in 0.3 $\mu \mathrm{l})$, followed by a systemic challenge of cocaine (COC; $10 \mathrm{mg} / \mathrm{kg}$ in 1 $\mathrm{ml} / \mathrm{kg}$, i.p.) or saline (SAL; $1 \mathrm{ml} / \mathrm{kg}$, i.p.), and then returned to the cage for $2 \mathrm{hr}$ of activity monitoring. Each subject experienced all four conditions (SAL-SAL, B/M-SAL, SAL-COC, B/M-COC). The order in which the conditions were presented was counterbalanced across subjects.

Statistics. For analysis of lever press data during reinstatement test sessions, a one- (condition) or two-way (condition $\times$ brain region) ANOVA was conducted, followed by Tukey's honest significant difference (HSD) post hoc comparisons. For microdialysis data the levels of DA or GLU were analyzed by using a two-way repeated measures ANOVA (time $\times$ condition), followed by post hoc comparisons, using a Bonferroni correction for multiple comparisons.

\section{Results}

Limbic and motor circuitry contributes to footshock-induced reinstatement of cocaine-seeking behavior

The effects of co-infusing the GABA agonist drugs baclofen and muscimol into various nuclei within the motive circuit before footshock-induced reinstatement of cocaine-seeking behavior are shown in Figure 1. Analysis of these data with a two-way brain
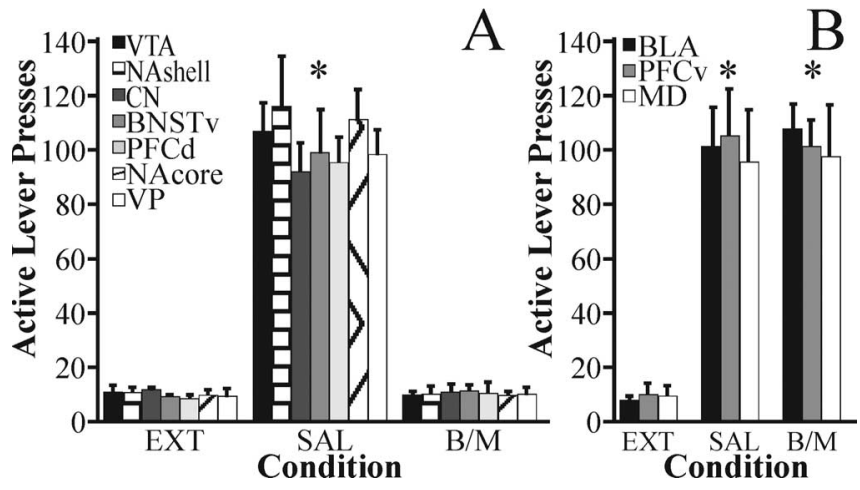

Figure 1. GABA agonist-induced inactivation of motor and limbic circuitries blocks footshock-induced reinstatement. Co-infusion of baclofen and muscimol (B/M, 0.3 and 0.03 $\mathrm{nmol} /$ side, respectively) into the VTA, NAshell, CN, BNSTv, PFCd, NAcore, or VP ( $A ; n=6-9$ for each group) before reinstatement testing blocked the ability of footshock stress to elicit reinstatement. The same treatment into the BLA, PFCV, or MD did not block renewed responding ( $B$; $n=6-9$ for each group). An asterisk indicates all groups significantly different from extinction responding (EXT); $p<0.05$.

region $\times$ treatment condition (extinction and saline or baclofen and muscimol pretreatment during reinstatement) ANOVA revealed significant main effects of treatment, $F_{(2,216)}=242.03$ and $p<0.001$, and brain region, $F_{(9,216)}=7.00$ and $p<0.001$, as well as a treatment $\times$ brain region interaction, $F_{(18,216)}=6.83$ and $p<$ 0.001 . Thus Tukey HSD post hoc analyses were conducted for each brain region to determine whether responding during saline or bac/mus reinstatement trials was significantly different from extinction responding. Inhibition of the central amygdala $(\mathrm{CN})$, ventral bed nucleus of the stria terminalis (BNSTv), nucleus accumbens shell (NAshell), ventral tegmental area (VTA), dorsal prefrontal cortex (PFCd), core of the nucleus accumbens (NAcore), or ventral pallidum (VP) blocked reinstatement responding elicited by footshock delivery (Fig. 1A). In contrast, inhibition of the basolateral amygdala (BLA), mediodorsal nucleus of the thalamus (MD), or ventral prefrontal cortex (PFCv) had no effect on renewed lever press responding (Fig. $1 B$ ). Thus both limbic (CN, BNSTv, NAshell, VTA) and motor (PFCd, NAcore, VP) nuclei comprise the circuit that underlies reinstatement responding elicited by footshock. Notably, on the basis of their morphology and connectivity, the CN, BNST, and NAshell have been conceptualized as a functional group termed the central extended amygdala (CEA) (Heimer et al., 1993; de Olmos and Heimer, 1999). It is hypothesized herein that stress activates the CEA and subsequently activates motor circuitry underlying behavioral output (i.e., PFCd, NAcore, and VP) via the VTA.

\section{Dopamine receptor antagonism within the dorsal prefrontal cortex blocks stress-induced reinstatement}

Previous work examining the circuitry underlying cocaineinduced reinstatement implicated a rise in DA within the PFCd, but not other DA terminal fields such as the NAcore and VP, as a preliminary step in activating cocaine-seeking behavior (McFarland and Kalivas, 2001). To assess whether dopamine input to the PFCd is also a critical component of footshock-induced reinstatement, we infused fluphenazine $\left(\mathrm{a}_{1}\right.$ and $\mathrm{D}_{2}$ receptor antagonist) into either the PFCd or NAcore, and we tested footshock for its ability to reinstate previously extinguished lever press responding. A two-way repeated measures ANOVA conducted on the data in Figure 2 revealed significant main effects of brain region, $F_{(1,17)}=46.08$ and $p<0.001$, and treatment condition, $F_{(2,34)}=182.19$ and $p<0.01$, as well as a brain region $\times$ treat- 


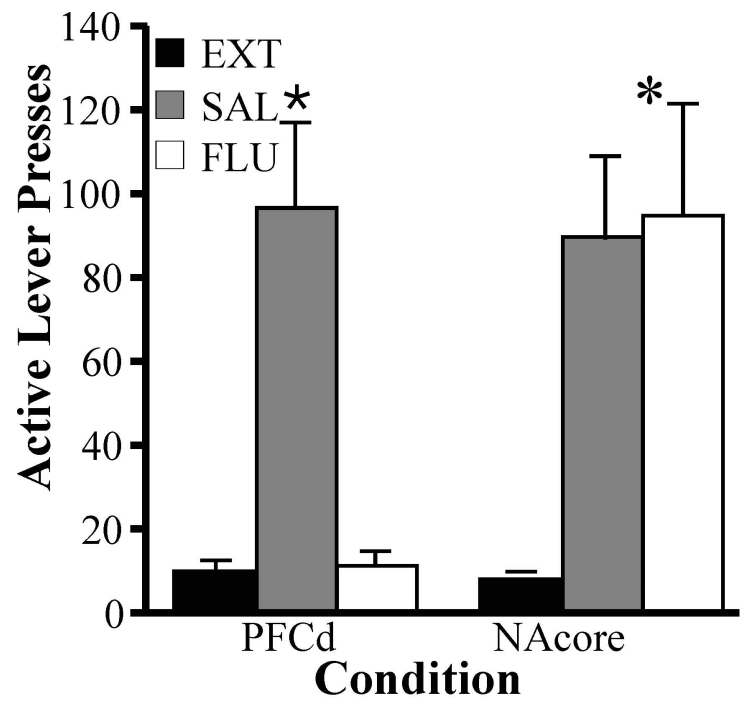

Figure 2. Role of dopamine in stress-induced reinstatement. Fluphenazine (FLU; $10 \mathrm{nmol} /$ side) pretreatment into the dorsal prefrontal cortex, but not the core of the nucleus accumbens, blocked footshock-induced reinstatement of cocaine-seeking behavior; $n=7$ for each group. An asterisk indicates $p<0.05$ compared with extinction responding (EXT).

ment condition interaction, $F_{(2,34)}=66.24$ and $p<0.001$. Subsequent Tukey HSD post hoc analyses showed that DA receptor antagonism within the PFCd, but not the NAcore, blocked stressinduced reinstatement of cocaine seeking, suggesting that VTA innervation of the PFCd (and subsequent motor circuitry) underlies footshock-induced reinstatement responding.

\section{Inhibition within the central extended amygdala blocks the rise in prefrontal dopamine associated with stress-induced reinstatement}

Previous studies have implicated the prefrontal cortex in behavioral responses to stress (Ravard et al., 1990; Duncan et al., 1993; Carlson et al., 1996; Di Chiara et al., 1999; Morrow et al., 1999). To examine further the role of the prefrontal cortex in stressinduced reinstatement of cocaine seeking, we conducted microdialysis for dopamine and glutamate in the PFC during reinstatement testing. Further, immediately before footshock presentation either saline or bac/mus was infused into the NAshell. The dopamine and glutamate levels in Figure 3 were analyzed separately with two-way treatment condition $\times$ time ANOVAs, with repeated measures on time. Significant main effects of treatment condition $\left[F_{(1,8)}=9.54\right.$ and $p<0.001$ and $F_{(1,8)}=4.10$ and $p<0.05$ for dopamine and glutamate, respectively $]$ and time $\left[F_{(18,144)}=5.207\right.$ and $p<0.001$ and $F_{(18,144)}=$ 3.47 and $p<0.001$ for dopamine and glutamate, respectively] as well as treatment condition $\times$ time interactions $\left[F_{(18,144)}=5.40\right.$ and $p<0.001$ and $F_{(18,144)}=2.32$ and $p<0.05$ for dopamine and glutamate, respectively] were found. Subsequent Bonferroni post hoc analyses with correction for multiple comparisons were used to determine at which time points the treatment groups significantly differed from one another as well as the time points at which dialysate levels were elevated significantly above baseline. Figure 3 shows that footshock presentation during the $10 \mathrm{~min}$ before beginning the reinstatement session resulted in a rise above preshock baseline in both dopamine (Fig. $3 B$; mean baseline for SAL and bac/mus-treated animals equal to $3.26 \pm 0.86$ and $2.60 \pm 0.96 \mathrm{fmol}$ per $10 \mathrm{~min}$ sample, respectively) and glutamate (Fig. 3A; mean baseline for SAL and bac/mus-treated animals equal to $12.25 \pm 3.48$ and $11.78 \pm 3.01$ pmol per $10 \mathrm{~min}$ sample, respectively) within the PFC during the shock presentation that extended into the reinstatement session. Inactivation of the NAshell with bac/mus completely blocked both the rise in dopamine and reinstatement responding (i.e., lever pressing; Fig. $3 C)$. Furthermore, inactivation produced a reduction in the shock-associated glutamate rise during the later part of the reinstatement session (Fig. 3A). Note the relatively large variability in glutamate levels within the prefrontal cortex resulting from infusion of bac/mus into the shell. This resulted from two distinct patterns of GLU responses during the reinstatement session. In one-half of the subjects $(n=4)$ inactivation of the NAshell produced no effect on footshock-induced rise in GLU, whereas in the other one-half of the subjects the rise in GLU was blocked completely. The reason for this dichotomy is not clear, because no difference in basal glutamate levels or the location of dialysis membranes or microinjection sites could be discerned. Nonetheless, it is clear that inactivation of the NAshell component of the CEA blocked the rise in DA in the prefrontal cortex that was critical for reinstatement responding.

\section{Inhibition of the dorsal prefrontal cortex blocks nucleus accumbens glutamate associated with footshock-induced reinstatement of cocaine-seeking behavior}

Because (1) the PFCd and the NAcore both were implicated in footshock-induced reinstatement (Fig. 1) and (2) cocaineinduced reinstatement of lever pressing has been shown to depend on the prefrontal glutamatergic projection to the NAcore (McFarland et al., 2003), the importance of the PFCd-NAcore glutamate projection in footshock-induced reinstatement of cocaine-seeking was examined. Microdialysis was conducted in the NAcore during stress-induced reinstatement testing to assess the effect of inactivating the PFCd on glutamate and dopamine levels. Analysis of the glutamate data shown in Figure $4 \mathrm{~A}$ revealed significant main effects of treatment condition, $F_{(1,9)}=13.58$ and $p<0.005$, and time, $F_{(18,162)}=5.22$ and $p<0.001$, as well as treatment condition $\times$ time interaction, $F_{(18,162)}=4.88$ and $p<$ 0.001 . Subsequent Bonferroni post hoc analyses were used to determine at which time points the treatment groups significantly differed from one another as well as the time points at which glutamate levels were elevated significantly above baseline. Footshock presentation during the $10 \mathrm{~min}$ preceding reinstatement testing resulted in a rise in glutamate within the NAcore beginning 20 min into the reinstatement session (Fig. $4 A$ ). Inactivating the PFCd with bac/mus blocked the rise in glutamate (baseline levels $12.11 \pm 2.72$ and $14.87 \pm 3.65 \mathrm{pmol} / \mathrm{sample}$ for SAL and $\mathrm{bac} /$ mus-treated animals, respectively) and concurrently blocked reinstatement responding (Fig. 4C). Analysis of the dopamine data (Fig. $4 B$ ) revealed no main effects of time, $F_{(18,162)}=1.20$ and $p>0.10$, or treatment condition, $F_{(1,9)}=1.70$ and $p>0.10$, and no treatment condition $\times$ time interaction, $F_{(18,162)}=0.82$ and $p>0.10$. Thus consistent with the previous finding that fluphenazine pretreatment into the NAcore had no effect on reinstatement responding (Fig. 2), footshock presentation did not result in a rise in accumbal dopamine (baseline levels $4.07 \pm 1.39$ and $4.17 \pm 0.93 \mathrm{fmol} / \mathrm{sample}$ for SAL and bac/mus-treated animals, respectively). The observed rise in glutamate was delayed relative to the rise in dopamine within the prefrontal cortex (Fig. 3 ) and relative to the rise observed during cocaine-induced reinstatement (McFarland et al., 2003). Accordingly, the time of the peak glutamate rise was compared with the time of peak lever pressing in $10 \mathrm{~min}$ time bins. There was a significant correlation between glutamate levels and lever pressing $(r=0.85 ; p<0.05$, two-tailed), with peak pressing (mean \pm SEM; $55.0 \pm 13.7 \mathrm{~min}$ ) 

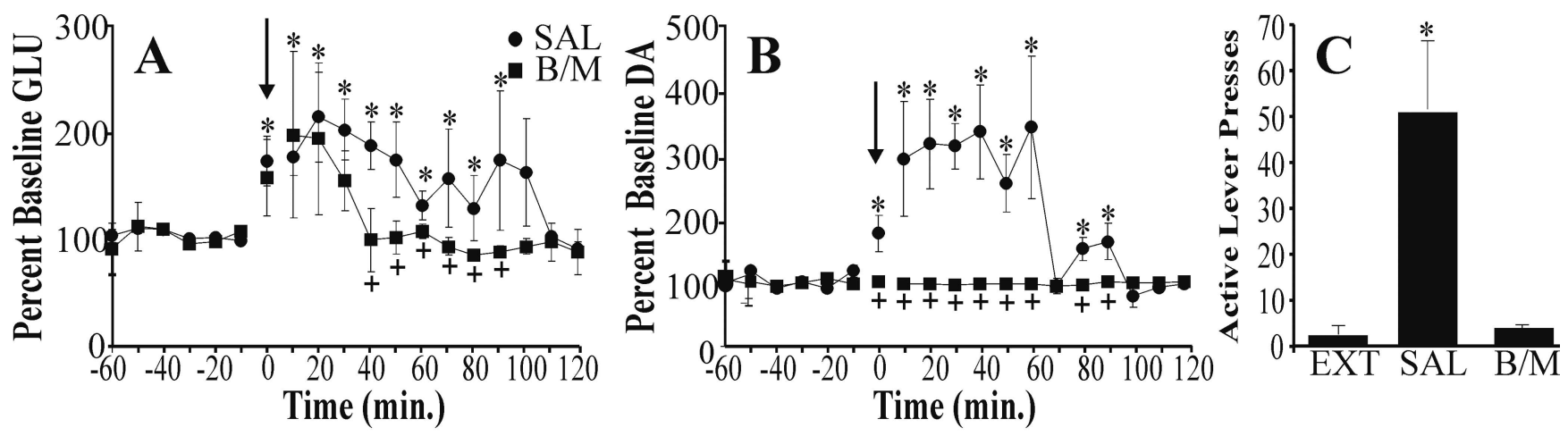

Figure 3. Prefrontal microdialysis during reinstatement elicited by footshock. Glutamate levels $(A)$ in the dorsal prefrontal cortex were elevated significantly in saline-pretreated rats (SAL; $n=$ 7) during the $10 \mathrm{~min}$ of intermittent footshock (arrow; 0 min time bin) and during $100 \mathrm{~min}$ of the reinstatement session. Inhibition of the NAshell with baclofen and muscimol (B/M; $n=6$ ) reduced the duration of the glutamate rise so that it was elevated above baseline for only 30 min of the reinstatement session. Dopamine levels ( $B$ ) also were elevated during footshock stress and the subsequent reinstatement session. Inactivation of the NAshell completely blocked footshock-induced elevations in prefrontal dopamine. Similarly, inactivation of the NAshell completely blocked reinstatement responding ( $C$ ). An asterisk indicates $p<0.05$ compared with baseline transmitter levels $(A, B)$ or extinction responding (EXT; $C$ ). A plus sign indicates significant difference between SAL and B/M pretreatment.
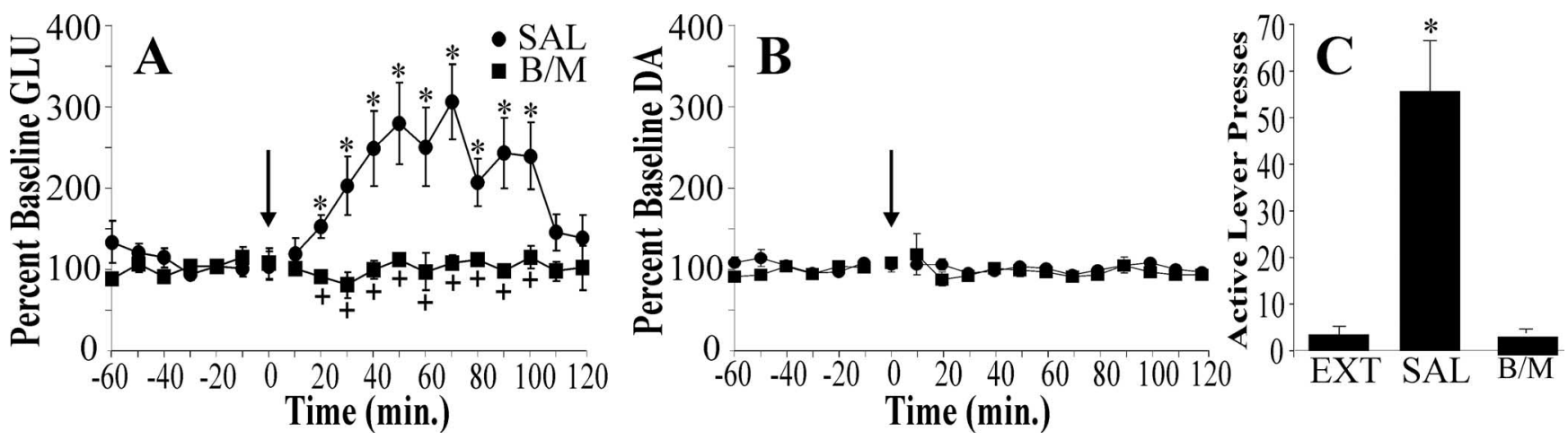

Figure 4. Nucleus accumbens core microdialysis during footshock-induced reinstatement. Footshock stress elicited a significant rise in glutamate ( $A$ ), but not dopamine ( $B$ ), in the core of the accumbens. The rise in glutamate did not occur until 20 min into the reinstatement session and lasted for 90 min. Both the rise in glutamate and reinstatement responding ( $C$ ) were prevented by baclofen and muscimol (B/M; $n=6$ ) pretreatment into the PFCd. An asterisk indicates $p<0.05$ as compared with baseline $(A)$ or extinction responding (EXT; $C$. A plus sign indicates significant difference between saline (SAL) and B/M pretreatment.

occurring on the rising phase of the glutamate curve (time to peak GLU, $66.7 \pm 13.8 \mathrm{~min}$ ). The fact that (1) inhibition of the glutamate projection from the PFCd to the NAcore blocked lever press responding and (2) the time course of the glutamate rise correlated with behavioral output suggests that the rise in NAcore glutamate underlies behavioral responding after footshock.

Locomotor activity and food-induced reinstatement of food seeking are unaffected by baclofen and muscimol infusion One possible explanation of the inhibition of cocaine-seeking behavior by baclofen and muscimol is that the treatment either results in impaired motoric capacity or impairs behaviors not specific to drug-related responding. Previously, we have demonstrated that bac/mus infusion into the VTA, PFCd, or NAcore did not inhibit locomotor behavior or food reinstatement (McFarland and Kalivas, 2001). However, in these previous studies the effect of bac/mus infusion into the CEA was not examined. Thus Figure 5 shows the effect of baclofen and muscimol infusion ( 0.3 / $0.03 \mathrm{nmol} / \mathrm{side}$ ) into the central nucleus (Fig. 5B) or NAshell (Fig. $5 C$ ) on spontaneous and cocaine-induced activity. It also shows the effect of such treatment on the reinstatement of previously extinguished food-seeking behavior elicited by noncontingent food delivery (Fig. 5A). A two-way brain region $\times$ treatment condition ANOVA conducted on the data in Figure $5 A$ revealed significant main effects of brain region, $F_{(1,17)}=69.34$ and $p<$
0.001 , and treatment condition, $F_{(2,17)}=21.11$ and $p<0.001$, and a significant brain region $\times$ treatment condition interaction $F_{(2,17)}=6.87$ and $p<0.001$. Tukey HSD post hoc analyses showed that food-seeking behavior was unaffected by bac/mus infusion into the $\mathrm{CN}$ and actually was enhanced after bac/mus infusion into the NAshell. Separate three-way systemic treatment (COC vs $\mathrm{SAL}) \times$ intracranial treatment $($ bac/mus vs $\mathrm{SAL}) \times$ time repeated measures ANOVAs were conducted on the locomotor activity data in Figure 5, $B$ and $C$. There were significant main effects of time $\left[F_{(17,459)}=12.62\right.$ and $p<0.001$ and $F_{(17,408)}=13.47$ and $p<0.001$ for NAshell and $\mathrm{CN}$, respectively] and systemic treatment $\left[F_{(1,27)}=18.45\right.$ and $p<0.001$ and $F_{(1,24)}=19.88$ and $p<$ 0.001 for NAshell and $\mathrm{CN}$, respectively] and a systemic treatment $\times$ time interaction $\left[F_{(17,459)}=10.34\right.$ and $p<0.001$ and $F_{(17,408)}=10.25$ and $p<0.001$ for NAshell and CN, respectively], but there was no main effect of intracranial treatment $\left[F_{(1,27)}=\right.$ 0.35 and $p>0.10$ and $F_{(1,24)}=0.32$ and $p>0.10$ for NAshell and $\mathrm{CN}$, respectively], no intracranial treatment $\times$ time interaction $\left[F_{(17,459)}=0.31\right.$ and $p>0.10$ and $F_{(17,408)}=0.62$ and $\left.p>0.10\right]$, and no time $X$ systemic treatment $X$ intracranial treatment interaction $\left[F_{(17,459)}=0.32\right.$ and $p>0.10$ and $F_{(17,408)}=0.31$ and $p>0.10]$. Thus cocaine significantly increased activity, and this locomotor enhancement was not altered by GABA agonist treatment into either the $\mathrm{CN}$ or the NAshell. 

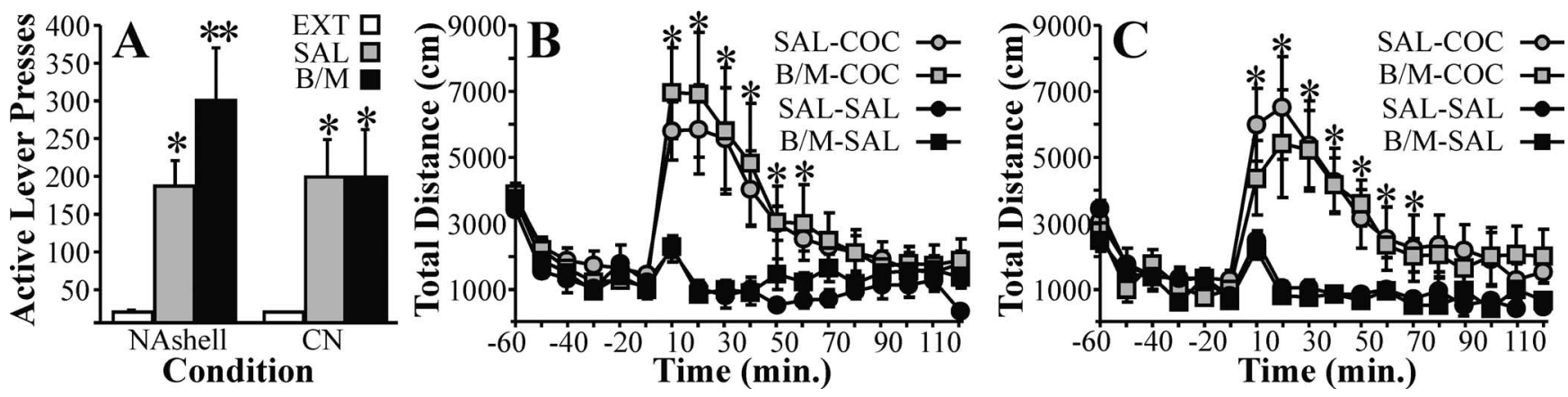

Figure 5. Response capacity is not impaired by baclofen and muscimol infusion into the nucleus accumbens shell or central nucleus of the amygdala. Infusion of baclofen and muscimol (B/M) into either the $\mathrm{CN}$ or NAshell did not impair reinstatement responding elicited by noncontingent food delivery $(A ; n=9$ per group). In fact, responding after $B / M$ infusion into the NAshell was enhanced significantly as compared with saline (SAL) infusion. Additionally, neither spontaneous nor cocaine-induced locomotor activity was impaired by B/M infusion into the CN ( $B ; n=8)$ or NAshell $(C ; n=$ 8). ${ }^{*} p<0.05$ compared with extinction responding (EXT; $\left.A\right)$ or spontaneous locomotor activity $(B, C) .{ }^{* *} p<0.05$ compared with SAL pretreatment.

\section{Histology}

Figure 6 shows microinjection locations for the inactivation studies according to the atlas of Paxinos and Watson (1998). PFCd infusions clustered around the border of the prelimbic and anterior cingulate cortices, with PFCv placements falling $\sim 2$ $\mathrm{mm}$ more ventral in the infralimbic cortex (Fig. 6A). NAcore placements centered on the anterior commissure, whereas NAshell placements fell medial and somewhat ventral to this closer to the midline (Fig. 6B). VP placements were subcommissural, in the lateral portion of the VP; Similarly, BNST injections sites were in the ventral part of the BNST (Fig. 6C). Figure $6 D$ shows $\mathrm{MD}, \mathrm{CN}$, and BLA injection sites. BLA sites were mainly in the anterior, rather than posterior, division, whereas $\mathrm{CN}$ sites covered both the medial and lateral divisions but tended not to fall within the posterior division. Microinjection sites for the dialysis, fluphenazine, and food studies fell within these same locations but, for clarity of the figure, are not shown.

Figure 7 shows the locations of microdialysis membranes in the PFC (Fig. 7A) and nucleus accumbens core (Fig. $7 B$ ). PFC membranes tended to span the prelimbic cortex, with the most dorsal part of the membranes falling within the anterior cingulate cortex. The most ventral tips tended to fall within the dorsal part of the infralimbic cortex. NAcore membranes spanned the NA around the anterior commissure, with the most dorsal parts of the membrane in the caudate-putamen and the most ventral tips in the shell subregion of the accumbens.

\section{Discussion}

Inactivation of the CN, BNSTv, NAshell, VTA, PFCd, NAcore, or VP blocked footshock-induced reinstatement of cocaine-seeking behavior. These nuclei presumably comprise the circuitry critical

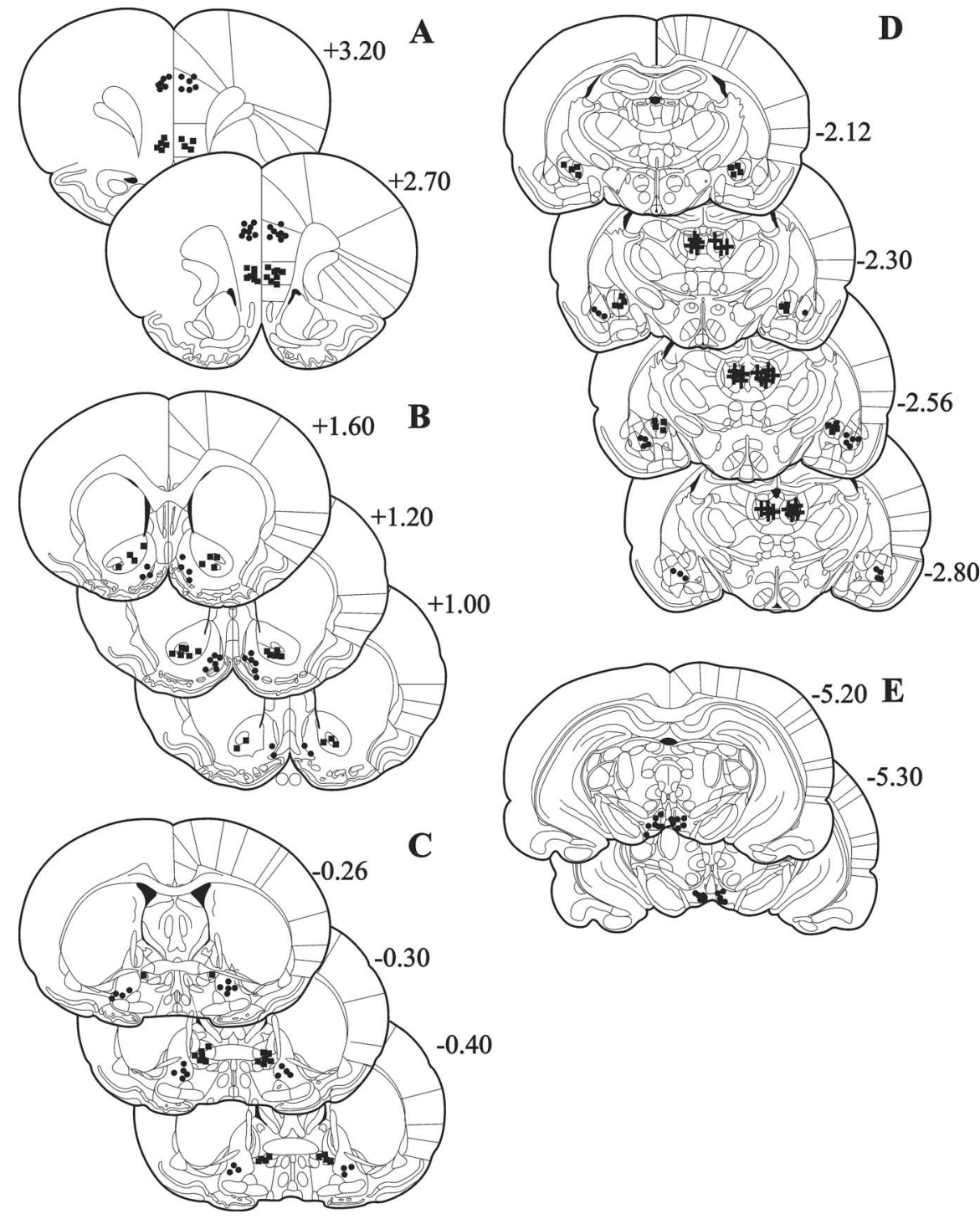

Figure 6. Microinjection sites. Shown are the microinfusion sites for inactivation of the dorsal $(\mathbf{O})$ and ventral $(\square)$ prefrontal cortex $(A)$; core $(\square)$ and shell $(-)$ of the nucleus accumbens $(B)$; ventral pallidum $(\mathbf{O})$ and ventral bed nucleus of the stria terminalis $(\mathbf{\square}$; $)$; central nucleus of the amygdala $(\mathbf{\square})$, basolateral amygdala $(\boldsymbol{O})$, and mediodorsal nucleus of the thalamus (+ ; $D$ ); and ventral tegmental area $(\mathbf{O} E)$. Microinjection sites for the microdialysis, fluphenazine, and food studies fell within these same locations but, for clarity of the figure, are not shown. Numbers represent the distance (in $\mathrm{mm}$ ) from bregma in the anteriorposterior plane. 

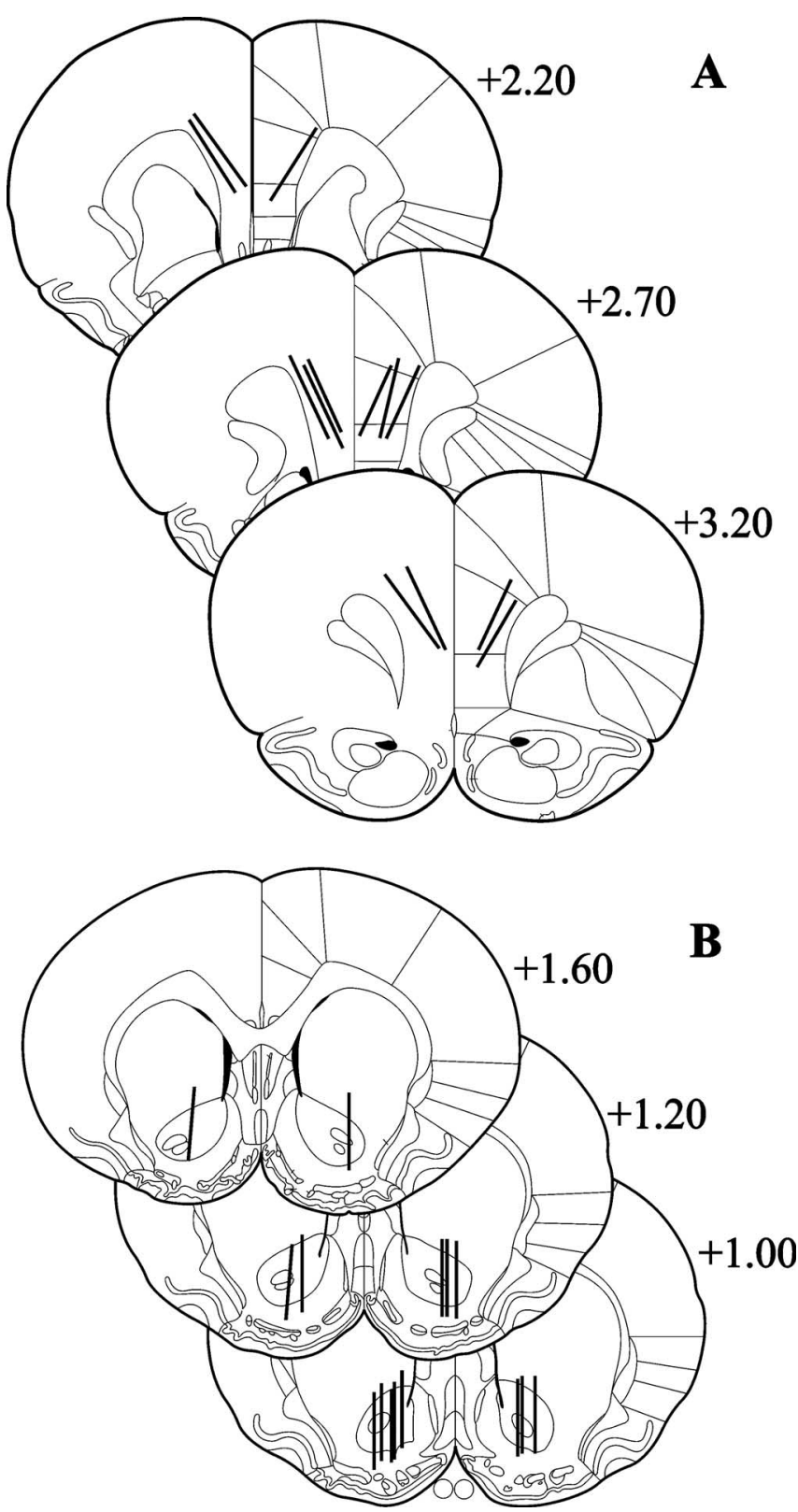

Figure 7. Microdialysis membranes. The locations of the microdialysis membranes are shown for the prefrontal cortex $(A)$ and nucleus accumbens $(B)$. Numbers represent the distance (in $\mathrm{mm}$ ) from bregma in the anterior-posterior plane.

for renewed lever press responding after stress. Notably, cocaineprimed reinstatement depends on activation of a VTA-PFCdNAcore-VP circuit (McFarland and Kalivas, 2001). Stressprimed reinstatement of cocaine seeking depends on activation of this same circuit plus additional limbic circuitry composed of the CN, BNSTv, and NAshell, together termed the CEA (Heimer et al., 1993; de Olmos and Heimer, 1999). The CEA presumably underlies processing of the emotional and behavioral significance of the footshock stressor and transmits this information to the motor circuitry involved in activating renewed drug-seeking behavior. Thus it is hypothesized that footshock activates the CEA, which in turn activates motor circuitry via a VTA dopaminergic projection.

The involvement of these nuclei is not attributable to nonspecific effects of baclofen and muscimol on response capacity. Baclofen and muscimol inactivation of the $\mathrm{CN}$ or NAshell produced no effect on either spontaneous or cocaine-induced locomotor activity. Further, such treatment did not decrease food-induced reinstatement of food-seeking behavior. In fact, bac/mus infusion into the NAshell actually enhanced responding. Previous research also has shown that the effects of baclofen and muscimol inactivation of the VTA, PFCd, NAcore, or VP on reinstatement responding are not attributable to motoric deficits (McFarland and Kalivas, 2001). These data suggest that, during baclofen and muscimol inactivation, response capacity remains intact.

\section{The role of the central extended amygdala in stress-induced reinstatement}

The importance of the CEA for footshock-induced reinstatement in the present study is consistent with previous studies demonstrating that processing within the $\mathrm{CN}$ and the BNST is involved in footshock-induced reinstatement for cocaine (Erb et al., 1996; Erb and Stewart, 1999). The stress-responsive neuropeptide corticotrophin-releasing factor (CRF) acts within the BNST during reinstatement responding (Erb and Stewart, 1999), and the CRF-containing pathway from the $\mathrm{CN}$ to the BNST is critical for footshock-induced reinstatement of cocaine-seeking behavior (Erb et al., 2001). Thus it seems likely that processing within the limbic circuitry is an early step in the production of stressinduced reinstatement. The present study extends these findings to suggest that the CEA, including the NAshell, which has not been examined previously, forms a functional unit underlying the ability of footshock to elicit cocaine-seeking behavior.

To assess the notion that the CEA depends on a dopamine projection to the PFCd to activate motor circuitry, we infused fluphenazine, a $D_{1} / D_{2}$ receptor antagonist, into either the PFCd or NAcore before reinstatement testing. Fluphenazine treatment into the PFCd, but not the NAcore, blocked footshock-induced reinstatement. Although it is possible that higher doses of fluphenazine are required in the NAcore compared with the PFCd, the dose that was used has been shown previously to have behavioral effects when infused into the nucleus accumbens (Hooks and Kalivas, 1995; Kim and Vezina, 1997). Thus it seems likely that the activation of motor circuitry depends on dopaminergic input to the PFCd, presumably from the VTA. Accordingly, Capriles et al. (2003) showed that blocking $\mathrm{D}_{1}$ receptors in the PFC blocked stress-induced reinstatement. Further, the microdialysis data show that footshock-induced reinstatement was associated with a rise in dopamine within the PFC. Importantly, both the rise in dopamine and reinstatement responding were blocked by inactivation of the NAshell, suggesting that processing within the CEA precedes processing within motor circuitry and that the CEA depends on a dopaminergic projection to the PFCd to activate motor circuitry. Further, the present finding that stress activation of PFC dopamine release depends on the NAshell identifies a novel mechanism by which stress can influence behavioral output.

Examination of the anatomical innervation of the VTA shows that the NAshell, CN, and BNSTv all send projections to the VTA (Usuda et al., 1998; Haber and Fudge, 2000; Georges and AstonJones, 2002). Projections from these nuclei are primarily GABAergic and peptidergic (Nagai et al., 1983; Oertel et al., 1983; Kalivas et al., 1993b; Sun and Cassell, 1993; Zahm et al., 2001a), with the most dense projection coming from the NAshell (Zahm et al., 2001b). However, the BNSTv also sends a glutamatergic projection to the VTA (Georges and Aston-Jones, 2002). It is clear that activity within each of these nuclei is critical for reinstatement because individual inactivation of each blocked footshock-induced responding, but the precise mechanism by 
which the CEA influences VTA firing has yet to be determined. One potential mechanism could be direct activation by the BNSTV and another the removal of inhibitory GABAergic modulation from the NAshell. Further experiments are required to determine the interaction of nuclei within the CEA and the relative importance of each projection to the VTA in stress-induced reinstatement. Additionally, because each nucleus within the CEA also receives a reciprocal dopaminergic projection from the VTA, a potential role for dopaminergic modulation of CEA output exists (i.e., that dopaminergic tone within the CEA influences its activation of the VTA and subsequent motor circuitry). Thus it also remains to be determined whether there is bidirectional flow of information within limbic circuitry underlying footshockinduced reinstatement.

\section{Prefrontal cortex and nucleus accumbens in stress-induced reinstatement}

The importance of medial prefrontal dopamine in footshockinduced reinstatement is consistent with previous research showing that stressful stimuli elicit increases in dopamine within the prefrontal cortex (Deutch and Roth, 1990; Gresch et al., 1994; Enrico et al., 1998). In the present experiment the inactivation of the dorsal prefrontal cortex blocked footshock-induced reinstatement of cocaine seeking (Capriles et al., 2003). Notably, cueprimed (McLaughlin and See, 2003) and cocaine-primed (McFarland and Kalivas, 2001) reinstatement also are blocked by inactivation of the dorsal prefrontal cortex. Because both stressand cocaine-primed reinstatements are blocked by dopamine receptor antagonist treatment in the PFCd (McFarland and Kalivas, 2001; Park et al., 2002; Capriles et al., 2003), activation of the PFCd by dopamine might serve as a common mechanism for instigating well learned cocaine-seeking behavior.

In addition to dopamine, the present data suggest a potential role for PFC glutamate in modulating stress-induced reinstatement. Thus footshock stress caused a rise in glutamate in the PFC during reinstatement testing. Inhibition of the NAshell significantly shortened the duration of the glutamate increase and blocked behavioral reinstatement. Because behavioral output is delayed with respect to the rise in PFC dopamine or glutamate and correlates temporally with the subsequent rise in glutamate within the accumbens, a premature termination of the glutamate response to footshock might contribute to a blockade of behavioral responding. The idea that prefrontal glutamate is a mechanism by which stress can influence behavioral processes is consistent with data demonstrating that (1) stress elicits a TTX-dependent rise in glutamate in the PFC (Moghaddam, 1993; Moghaddam et al., 1994), and (2) a blockade of AMPA receptors in the PFC blocks the stress-induced rise dopamine (Jedema and Moghaddam, 1994; Takahata and Moghaddam, 1998). Thus a rise in PFC glutamate during footshock-induced reinstatement could modulate the rise in prefrontal dopamine on which footshock-induced reinstatement depends; however, a full characterization of the effect remains for future examination.

It is our hypothesis that a rise in dopamine, and perhaps glutamate, in the PFC activates a PFC-NAcore-VP motor output pathway. Consistent with this notion, inactivation of each of these structures blocked stress-induced reinstatement of cocaine seeking. To verify further that the PFC glutamate projection to the NAcore was activated, we conducted microdialysis within the NAcore during reinstatement trials. Footshock presentation led to an increase in glutamate (but not dopamine) within the core of the accumbens that was blocked by inhibition of the dorsal prefrontal cortex before footshock delivery. Further, the time of the peak rise in glutamate within the NAcore correlated with the time at which lever presses were most frequent. These data suggest that footshock-induced reinstatement depends on PFC glutamatergic activation of the NAcore and subsequent motor circuitry. The importance of the glutamatergic projection from the PFCd to the NAcore in stress-induced reinstatement is consistent with previous data demonstrating the importance of this pathway for cocaine-induced reinstatement (McFarland et al., 2003) and suggests that it plays a general role in the production of cocaineseeking behavior by multiple stimuli capable of eliciting relapse to cocaine seeking.

\section{Conclusions}

The present study identifies a CEA-VTA-motor (PFCd-NAcoreVP) circuit underlying footshock-induced reinstatement of cocaine seeking. Although the motor subcircuit might serve as a general motor output pathway for drug-seeking behavior elicited by many kinds of stimuli (e.g., stress, cues, and drug), the limbic subcircuit seems unique to stress-induced reinstatement (vs cue- or drugprimed reinstatement). Within the limbic subcircuit, cocaineprimed reinstatement requires only activation of the VTA (McFarland and Kalivas, 2001), whereas cue-primed reinstatement depends on activation of the basolateral amygdala (Meil and See, 1997; Kantak et al., 2002), and stress-primed reinstatement depends on the CEA. Thus the sensory and emotional attributes of the stimulus govern its processing within limbic circuitry. This suggests that different stimuli capable of eliciting relapse are processed differentially within limbic circuitry but share the ability to activate the PFC and subsequent motor circuitry, perhaps by increasing PFC dopamine levels. Further, activation of motor circuitry depends on a glutamatergic projection from the PFCd to the NAcore.

\section{References}

Ahmed SH, Koob GF (1997) Cocaine- but not food-seeking behavior is reinstated by stress after extinction. Psychopharmacology (Berl) 132:289-295.

Alderson HL, Parkinson JA, Robbins TW, Everitt BJ (2001) The effects of excitotoxic lesions of the nucleus accumbens core or shell regions on intravenous heroin self-administration in rats. Psychopharmacology (Berl) 153:455-463.

Baker G, McGregor A, Roberts DCS (1994) Effect of 6-hydroxydopamine lesions of the amygdala on intravenous cocaine self-administration under a progressive ratio schedule of reinforcement. Brain Res 646:273-278.

Baker G, McGregor A, Roberts DCS (1996) Effect of 6- hydroxydopamine lesions of the medial prefrontal cortex on intravenous cocaine selfadministration under a progressive ratio schedule of reinforcement. Pharmacol Biochem Behav 53:5-9.

Bradberry CW, Barrett-Larimore RL, Jatlow P, Rubino SR (2000) Impact of self-administered cocaine and cocaine cues on extracellular dopamine in mesolimbic and sensorimotor striatum in rhesus monkeys. J Neurosci 20:3874-3883.

Brown EE, Fibiger HC (1993) Differential effects of excitotoxic lesions of the amygdala on cocaine-induced conditioned locomotion and conditioned place preference. Psychopharmacology (Berl) 113:123-130.

Capriles N, Rodaros D, Sorge RE, Stewart J (2003) A role for the prefrontal cortex in stress- and cocaine-induced reinstatement of cocaine seeking in rats. Psychopharmacology (Berl) 168:66-74.

Carelli RM, Ijames SG (2000) Nucleus accumbens cell firing during maintenance, extinction, and reinstatement of cocaine self-administration behavior in rats. Brain Res 866:44-54.

Carlson JN, Visker KE, Keller Jr RW, Glick SD (1996) Left and right 6-hydroxydopamine lesions of the medial prefrontal cortex differentially alter subcortical dopamine utilization and the behavioral response to stress. Brain Res 711:1-9.

Chang JY, Janak PH, Woodward DJ (2000) Neuronal and behavioral correlations in the medial prefrontal cortex and nucleus accumbens during cocaine self-administration by rats. Neuroscience 99:433-443.

Childress AR, Mozley PD, McElgin W, Fitzgerald J, Reivich M, O’Brien CP 
(1999) Limbic activation during cue-induced cocaine craving. Am J Psychiatry 156:11-18.

Cousins MS, Trevitt J, Atherton A, Salamone JD (1999) Different behavioral functions of dopamine in the nucleus accumbens and ventrolateral striatum: a microdialysis and behavioral investigation. Neuroscience 91:925-934.

de Olmos JS, Heimer L, editors (1999) The concepts of the ventral striatopallidal system and extended amygdala. New York: The New York Academy of Sciences.

Deutch AY, Roth RH (1990) The determinants of stress-induced activation of the prefrontal cortical dopamine system. Prog Brain Res 85:357-393.

Di Chiara G, Loddo P, Tanda G (1999) Reciprocal changes in prefrontal and limbic dopamine responsiveness to aversive and rewarding stimuli after chronic mild stress: implications for the psychobiology of depression. Biol Psychiatry 46:1624-1633.

Duncan GE, Johnson KB, Breese GR (1993) Topographic patterns of brain activity in response to swim stress: assessment by 2-deoxyglucose uptake and expression of Fos-like immunoreactivity. J Neurosci 13:3932-3943.

Enrico P, Bouma M, de Vries J, Westerink B (1998) The role of afferents to the ventral tegmental area in the handling stress-induced increase in the release of dopamine in the medial prefrontal cortex: a dual-probe microdialysis study in the rat brain. Brain Res 779:205-213.

Erb S, Stewart J (1999) A role for the bed nucleus of the stria terminalis, but not the amygdala, in the effects of corticotropin-releasing factor on stressinduced reinstatement of cocaine seeking. J Neurosci 19:RC35(1-6).

Erb S, Shaham Y, Stewart J (1996) Stress reinstates cocaine-seeking behavior after prolonged extinction and a drug-free period. Psychopharmacology (Berl) 128:408-412.

Erb S, Salmaso N, Rodaros D, Stewart J (2001) A role for the CRFcontaining pathway from central nucleus of the amygdala to bed nucleus of the stria terminalis in the stress-induced reinstatement of cocaine seeking in rats. Psychopharmacology (Berl) 158:360-365.

Garavan H, Pankiewicz J, Bloom A, Cho JK, Sperry L, Ross TJ, Salmeron BJ, Risinger R, Kelley D, Stein EA (2000) Cue-induced cocaine craving: neuroanatomical specificity for drug users and drug stimuli. Am J Psychiatry 157:1789-1798.

Georges F, Aston-Jones G (2002) Activation of ventral tegmental area cells by the bed nucleus of the stria terminalis: a novel excitatory amino acid input to midbrain dopamine neurons. J Neurosci 22:5173-5187.

Gong W, Neill DB, Justice Jr JB (1997) 6-Hydroxydopamine lesion of the ventral pallidum blocks acquisition of place preference conditioning to cocaine. Brain Res 754:103-112.

Gresch PJ, Sved AF, Zigmond MJ, Finlay JM (1994) Stress-induced sensitization of dopamine and norepinephrine efflux in medial prefrontal cortex of the rat. J Neurochem 63:575-583.

Grimm JW, See RE (2000) Dissociation of primary and secondary rewardrelevant limbic nuclei in an animal model of relapse. Neuropsychopharmacology 22:473-479.

Groenewegen HJ, Wright CI, Beijer VJ (1996) The nucleus accumbens: gateway for limbic structures to reach the motor system? Prog Brain Res 107:485-551.

Haber S, Fudge J (2000) The central nucleus of the amygdala projection to dopamine subpopulations in primates. Neuroscience 97:479-494.

Heimer L, Alheid GF, Zahm DS (1993) Basal forebrain organization: an anatomical framework for motor aspects of drive and motivation. In: Limbic motor circuits and neuropsychiatry (Kalivas PW, Barnes CD, eds), pp 1-32. Boca Raton, FL: CRC.

Hooks MS, Kalivas PW (1995) The role of mesoaccumbens-pallidal circuitry in novelty-induced behavioral activation. Neuroscience 64:587-598.

Jedema HP, Moghaddam B (1994) Glutamatergic control of dopamine release during stress in the rat prefrontal cortex. J Neurochem 63:785-788.

Kalivas PW, Churchill L, Klitenick MA (1993a) The circuitry mediating the translation of motivational stimuli into adaptive motor responses. In: Limbic motor circuits and neuropsychiatry (Kalivas PW, Barnes CD, eds), pp 237-287. Boca Raton, FL: CRC.

Kalivas PW, Churchill L, Klitenick MA (1993b) GABA and enkephalin projection from the nucleus accumbens and ventral pallidum to VTA. Neuroscience 57:1047-1060.

Kantak KM, Black Y, Valencia E, Green-Jordan K, Eichenbaum HB (2002) Dissociable effects of lidocaine inactivation of the rostral and caudal ba- solateral amygdala on the maintenance and reinstatement of cocaineseeking behavior in rats. J Neurosci 22:1126-1136.

Kilts CD, Schweitzer JB, Quinn CK, Gross RE, Faber TL, Muhammad F, Ely TD, Hoffman JM, Drexler KP (2001) Neural activity related to drug craving in cocaine addiction. Arch Gen Psychiatry 58:334-341.

Kim JH, Vezina P (1997) Activation of metabotropic glutamate receptors in the rat nucleus accumbens increases locomotor activity in a dopaminedependent manner. J Pharmacol Exp Ther 283:962-968.

Kosobud AEK, Harris GC, Chapin JK (1994) Behavioral associations of neuronal activity in the ventral tegmental area of the rat. J Neurosci 14:7117-7129.

McAlonan GM, Robbins TW, Everitt BJ (1993) Effects of medial dorsal thalamic and ventral pallidal lesions on the acquisition of a conditioned place preference: further evidence for the involvement of the ventral striatopallidal system in reward-related processes. Neuroscience 52:605-620.

McFarland K, Kalivas PW (2001) The circuitry mediating cocaine-induced reinstatement of drug-seeking behavior. J Neurosci 21:8655-8663.

McFarland K, Lapish CC, Kalivas PW (2003) Prefrontal glutamate release into the core of the nucleus accumbens mediates cocaine-induced reinstatement of drug-seeking behavior. J Neurosci 23:3531-3537.

McLaughlin J, See RE (2003) Selective inactivation of the dorsomedial prefrontal cortex and the basolateral amygdala attenuates conditioned-cued reinstatement of extinguished cocaine-seeking behavior in rats. Psychopharmacology (Berl) 168:57-65.

Meil WM, See RE (1997) Lesions of the basolateral amygdala abolish the ability of drug-associated cues to reinstate responding during withdrawal from self-administered cocaine. Behav Brain Res 87:139-148.

Mogenson GJ, Jones DJ, Yim CY (1980) From motivation to action: functional interface between the limbic system and the motor system. Prog Neurobiol 14:69-97.

Moghaddam B (1993) Stress preferentially increases extraneuronal levels of excitatory amino acids in the prefrontal cortex: comparison to hippocampus and basal ganglia. J Neurochem 60:1650-1657.

Moghaddam B, Bolinao ML, Stein-Behrens B, Sapolsky R (1994) Glucocorticoids mediate the stress-induced extracellular accumulation of glutamate. Brain Res 655:251-254.

Morrow BA, Elsworth JD, Rasmusson AM, Roth RH (1999) The role of mesoprefrontal dopamine neurons in the acquisition and expression of conditioned fear in the rat. Neuroscience 92:553-564.

Nagai T, McGeer PL, McGeer EG (1983) Distribution of GABA-T-intensive neurons in the rat forebrain and midbrain. J Comp Neurol 218:220-238.

Neisewander JL, O’Dell LE, Tran-Nguyen LT, Castaneda E, Fuchs RA (1996) Dopamine overflow in the nucleus accumbens during extinction and reinstatement of cocaine self-administration behavior. Neuropsychopharmacology 15:506-514.

Oertel WH, Riethmuller G, Mugnaini E, Schmechel DE, Weindl A, Gramsch C, Herz A (1983) Opioid peptide-like immunoreactivity localized in GABAergic neurons of rat neostriatum and central amygdaloid nucleus. Life Sci 33[Suppl 1]:73-76.

Park WK, Bari AA, Jey AR, Anderson SM, Spealman RD, Rowlett JK, Pierce RC (2002) Cocaine administered into the medial prefrontal cortex reinstates cocaine-seeking behavior by increasing AMPA receptor-mediated glutamate transmission in the nucleus accumbens. J Neurosci 22:2916-2925.

Parkinson JA, Olmstead MC, Burns LH, Robbins TW, Everitt BJ (1999) Dissociation in effects of lesions of the nucleus accumbens core and shell on appetitive Pavlovian approach behavior and the potentiation of conditioned reinforcement and locomotor activity by D-amphetamine. J Neurosci 19:2401-2411.

Paxinos G, Watson C (1998) The rat brain in stereotaxic coordinates, Ed 4. New York: Academic.

Ravard S, Carnoy P, Herve D, Tassin JP, Thiebot MH, Soubrie P (1990) Involvement of prefrontal dopamine neurones in behavioural blockade induced by controllable versus uncontrollable negative events in rats. Behav Brain Res 37:9-18.

Schultz W, Apicella P, Ljungberg T (1993) Responses of monkey dopamine neurons to reward and conditioned stimuli during successive steps of learning a delayed response task. J Neurosci 13:900-913.

Shalev U, Morales M, Hope B, Yap J, Shaham Y (2001) Time-dependent changes in extinction behavior and stress-induced reinstatement of drug seeking following withdrawal from heroin in rats. Psychopharmacology (Berl) 156:98-107. 
Sun N, Cassell MD (1993) Intrinsic GABAergic neurons in the rat central extended amygdala. J Comp Neurol 330:381-404.

Takahata R, Moghaddam B (1998) Glutamatergic regulation of basal and stimulus-activated dopamine release in the prefrontal cortex. J Neurochem 71:1443-1449.

Usuda I, Tanaka K, Chiba T (1998) Efferent projections of the nucleus accumbens in the rat with special reference to subdivision of the nucleus: biotinylated dextran amine study. Brain Res 797:73-93.

Volkow ND, Wang GJ, Fowler JS, Hitzemann R, Angrist B, Gatley SJ, Logan J, Ding YS, Pappas N (1999) Association of methylphenidate-induced craving with changes in right striato-orbitofrontal metabolism in cocaine abusers: implications in addiction. Am J Psychiatry 156:19-26.

Weiss F, Martin-Fardon R, Ciccocioppo R, Kerr TM, Smith DL, Ben-Shahar $\mathrm{O}$ (2001) Enduring resistance to extinction of cocaine-seeking behavior induced by drug-related cues. Neuropsychopharmacology 25:361-372.

Westerink BHC (1995) Brain microdialysis and its application for the study of animal behaviour. Behav Brain Res 70:103-124.

Zahm DS, Brog JS (1992) On the significance of subterritories in the "accumbens" part of the rat ventral striatum. Neuroscience 50: $751-767$.

Zahm DS, Grosu S, Williams EA, Qin S, Berod A (2001a) Neurons of origin of the neurotensinergic plexus enmeshing the ventral tegmental area in rat: retrograde labeling and in situ hybridization combined. Neuroscience 104:841-851

Zahm DS, Williams EA, Latimer MP, Winn P (2001b) Ventral mesopontine projections of the caudomedial shell of the nucleus accumbens and extended amygdala in the rat: double dissociation by organization and development. J Comp Neurol 436:111-125. 